\title{
Diagnóstico de plagas y enfermedades de cinco genotipos de ajíes (Capsicum sp.) en invernadero
}

\section{Diagnosis of pests and diseases of five genotypes of peppers (Capsicum sp.) in greenhouse}

Angel Fernando Huaman Pilco ${ }^{1 *}\left(\mathbb{D}\right.$, Elder Chichipe Vela ${ }^{1}$, Edith Calderón Ordoñez ${ }^{1}$, Santos Triunfo Leiva Espinoza'(D), Manuel Oliva ${ }^{1}$ (ID

\section{RESUMEN}

El Perú es probablemente el país con más diversidad nativa de ají cultivado en el mundo. En este contexto, el objetivo de esta investigación fue diagnosticar las plagas y enfermedades de cinco genotipos de ají (Capsicum sp.), cultivadas en condiciones de un invernadero semicontrolado. El experimento se instaló bajo un Diseño Completamente al Azar (DCA) con cinco genotipos de aji. Se evaluó la incidencia de plagas y enfermedades. En laboratorio se realizó la caracterización morfológica de las plagas y enfermedades encontradas. Las enfermedades identificadas fueron pudrición de frutos causada por Penicillium sp y pudrición vascular causada por Fusarium sp. Se presentaron solo para el ají pimiento con incidencias del 3,8 \% y 8,3 \% respectivamente. La única plaga que se presento fue el pulgón verde identificado como Myzus sp, que se presentó en todos los tratamientos, pero con mayor incidencia en ají pimiento con un promedio de 34,33 pulgones/in 2 .

Palabras clave: diagnostico, Penicillium sp., Fusarium sp., Myzus sp., Capsicum sp.

\begin{abstract}
Peru is probably the country with the greatest native diversity of cultivated chili peppers in the world. In this context, the objective of this research was to diagnose the pests and diseases of five genotypes of chili peppers (Capsicum sp.), grown under semi-controlled greenhouse conditions. The experiment was set up under a Randomized Complete Design (RCD) with five chilli pepper varieties. The incidence of pests and diseases was evaluated. The morphological characterization of the pests and diseases found was carried out in the laboratory. The diseases identified were fruit rot caused by Penicillium sp and vascular rot caused by Fusarium sp. They were presented only for pepper with incidences of $3.8 \%$ and $8.3 \%$ respectively. The only pest that occurred was the green aphid identified as Myzus sp, which was present in all treatments, but with a higher incidence in pepper with an average of 34.33 aphids/in ${ }^{2}$.
\end{abstract}

Keywords: diagnosis, Penicillium sp, Fusarium sp, Myzus sp, Capsicum sp.

${ }^{1}$ Universidad Nacional Toribio Rodríguez de Mendoza de Amazonas, Instituto de Investigación para el Desarrollo Sustentable de Ceja de Selva, Chachapoyas, Perú

"Autor de Correspondencia, e-mail: anfer.hp13@gmail.com 


\section{INTRODUCCIÓN}

El Perú se caracteriza por tener la mayor diversidad de ajíes cultivados del mundo y por contar con una gran cantidad de ajíes silvestres (Ugas, 2012). El ají es un cultivo susceptible a sufrir un complejo número de plagas y enfermedades (Chew et al., 2008). En este sentido Beltrano y Gimenez (2015) mencionan que organismos como los insectos, hongos, bacterias, nematodos y virus, causan serias pérdidas económicas. Adicionalmente existen otros patógenos de importancia secundaria como los fitoplasmas y los viroides.

Por otro lado, la producción de verduras y hortalizas puede realizarse en ambientes cerrados, aislados y controlados como son los sistemas de producción bajo invernadero. Estos ambientes ofrecen condiciones ideales de producción hortícola (Juárez et al., 2011). Sin embargo, algunos ambientes no cuentan con la tecnología suficiente. No se controla condiciones como humedad y aireación, lo que favorece la aparición y el desarrollo de plagas y enfermedades (Beatriz, 2015). Además, en los invernaderos se manejan cultivos de forma intensiva. Estos normalmente están sometidos a un laboreo y manipulación constante, ayudando a la diseminación de plagas y enfermedades, particularmente bacterias o virus que se transmiten mecánicamente (FAO, 2002).

En la región Amazonas, una alternativa de producción de ajíes es en invernadero. La Universidad Nacional Toribio Rodríguez de Mendoza, en su afán de generar conocimiento vinculado al cultivo de ají, tiene instalado invernaderos semicontrolados donde, sin embargo, es posible notar la presencia de plagas y enfermedades. Por esta razón, en la presente investigación se planteó el objetivo de diagnosticar las plagas y enfermedades de cinco genotipos de ajíes (Capsicum sp.), cultivadas en un invernadero semicontrolado en el distrito de Huambo, provincia de Rodríguez de Mendoza, así como registrar el comportamiento del cultivo de ají bajo este sistema de producción.

\section{MATERIALES Y MÉTODOS}

\section{Área de estudio}

La investigación se realizó en el invernadero de la estación experimental del Instituto de Investigación para el Desarrollo Sustentable de Ceja de Selva (INDES-CES) en el distrito de Huambo, Rodríguez de Mendoza, en las coordenadas $6^{\circ} 20^{\prime} 10^{\prime \prime} \mathrm{S}$ y $77^{\circ} 27^{\prime}$ 58 " O, a una altitud de 1630 m.s.n.m y con una temperatura promedio de $18^{\circ}$ Instalación del experimento Se instaló en un invernadero de $9 \mathrm{~m}$ de ancho y $12 \mathrm{~m}$ de largo, considerando un Diseño Completamente al Azar (DCA) con 5 genotipos de ají, las cuales fueron: pimiento (Capsicum annuum), escabeche (Capsicum baccatum), charapita (Capsicum chinense), pucunucho (Capsicum chinense) y pipi de mono (Capsicum frutescen).

Las semillas luego del pre germinado se colocaron individualmente en bandeja de germinación. Cuando las plántulas alcanzaron una altura entre 10 a $15 \mathrm{~cm}$, se realizó el trasplante a mangas plásticas, que contenían como sustrato un $75 \%$ de pajilla de arroz y un $25 \%$ de arena. También contenía el sistema de fertirriego con dos tipos de soluciones con macro y micro nutrientes recomendado por Universidad Nacional Agraria La Molina (UNALM). Las labores como el deshierbo, se realizaron durante todo el desarrollo del cultivo. Para evitar el acame de plantas, las plantas de ají se sujetaron con clips en un sistema de tutorado previamente instalado.

\section{Evaluación de plagas}

Se evaluaron 4 plantas de cada genotipo elegidas al azar. El conteo de pulgones adultos se tomó de un área de $1,27 \mathrm{~cm}^{2}$ de hoja por planta respectivamente, adaptado de la metodología utilizada por Belmontes y Castañeda Cabrera (2015). Los individuos fueron colocados en envases herméticos con su respectiva codificación y fecha de recolección. Estas muestras fueron trasladadas al Laboratorio de Investigación en Sanidad Vegetal (LABISANV) para su respectiva identificación. Su uso un estereoscopio marca Carl Zeiss modelo SteREO Discovery V8, para observar las características morfológicas. Se usaron las claves 
taxonómicas descritas por Cabello et al. (1997), Simbaqueba et al. (2014) y Navarro y García-Marí (2014), para la identificación.

\section{Evaluación de enfermedades}

Para determinar la incidencia de enfermedades se hizo una evaluación simple contabilizando la proporción de plantas enfermas. Se considera una plata enferma a aquella que muestra cualquier síntoma en hojas, tallos y frutos (Agrios, 1995).

Se extrajeron hojas, frutos y raíces de las plantas que presentaron signos y síntomas, que indicaban presencia de la enfermedad. Los materiales utilizados se esterilizaron con alcohol y las muestras vegetales se envasaron en bolsas de papel para absorber el exceso de humedad. Posteriormente, se guardó en un envase de plástico con su respectiva codificación y se trasladó inmediatamente al laboratorio para proceder con el trabajo (Tomalo, 2015).

\section{Aislamiento en medio de cultivo}

Se procedió a tomar porciones de tejido enfermo para desinfectarlos en alcohol al 75\%. Se lavó dos veces con agua desmineralizada y se eliminó su exceso. Posteriormente se introdujo en una placa Petri estéril con agar papa dextrosa (PDA). La incubación se realizó a $23,5^{\circ} \mathrm{C}$ por un periodo de 7 días, revisando periódicamente el desarrollo del micelio del hongo (Tomalo, 2015).

\section{Caracterización morfológica}

Se procedió a separar las estructuras del hongo de la placa Petri, haciendo uso de una tira de cinta adhesiva de $4 \mathrm{~cm}$. Después se adicionó una gota de agua destilada sobre el portaobjetos y se pegó la cinta sobre el portaobjetos para luego ser observado en el microscopio con cámara incorporada marca Carl Zeiss modelo Primo Star.

Para la caracterización se tomaron en cuenta las características más importantes de los hongos descritos por Agrios (1995). Sus esporas y cuerpos fructíferos y hasta cierto grado las características de su soma (plasmodio o micelio). También se consideró la forma de los conidios y conidióforos descritos según Ellis (1971) y Barnett y Hunter (1998).

\section{Análisis de datos}

Los datos de las variables agronómicas obtenidos se analizaron bajo un diseño completo al azar. Se realizó una prueba de contraste de normalidad de Shapiro Wilk. Una vez comprobada la normalidad, se realizó un análisis de varianza (ANOVA). La interacción entre los factores se realizó mediante la prueba de comparaciones múltiples de Tukey. Todos los análisis estadísticos se realizaron a un nivel de significancia de $P<0.05$ con el software IBM SPSS v. 23.

\section{Identificación de la plaga 1}

Los individuos de la plaga 1 , fueron insectos ápteros de color verde amarillento claro; con un tamaño de 1 a $10 \mathrm{~mm}$; alados y con cabeza y tórax oscuro; con la cabeza tipo opistognata con aparato bucal dirigido hacia abajo y hacia atrás; antena de tipo filiforme; con el tubérculo antenal bien desarrollado y el lado interior ligeramente divergente; patas de tipo caminador o cursorias, con las tibias más largas que los fémures; alas membranosas y sifones largos y convergentes con ápice oscuro (Simbaqueba et al., 2014; Ortego, Difabio, \& Mier Durante, 2004) (Figura 1).

Por otro lado, esta plaga se presentó solo en la etapa de desarrollo de fructificación. Sin embargo, se encontró el mayor índice de infestación en la especie de ají pimiento. Los genotipos charapita, escabeche, pucunucho y pipi de mono presentaron menor índice de infestación en esta etapa. Se notó un retraso en el crecimiento de órganos vegetativos y el amarillamiento de la planta. También se observó deformaciones de hojas como enrollamientos y curvaturas.

\section{Identificación de enfermedad 1}

Síntomas

Se observó pudrición con mayor presencia en frutos maduros para el ají pimiento. Al principio se presentaron manchas superficiales blandas, aguanosas, ligeramente decoloradas y de tamaño variable, luego estas manchas se empezaron a hundir con rapidez y a descomponer parte del fruto. Poco después, un moho blanco comenzó a crecer sobre la superficie de la cáscara del fruto, cerca de la parte central de la mancha 


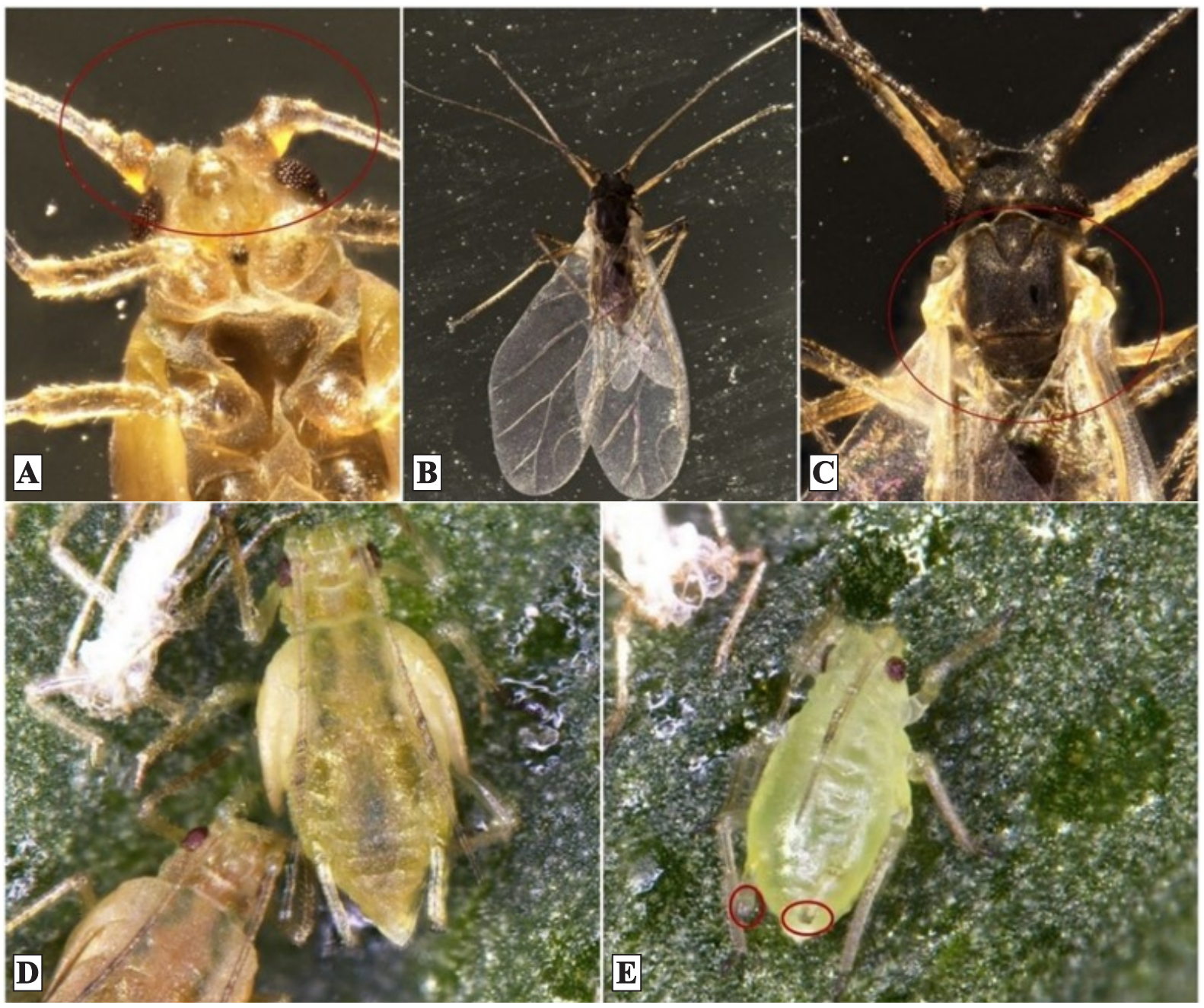

Figura 1. Características. A, Tubérculo antena desarrollado, antenas ligeramente convergentes. B, Adultos alados de color oscuro. C, Adulto alado con tórax de color negro, de apariencia coriácea. D, Adultos ápteros de cuerpo color verde- amarillento a veces rosáceo. E, Ápice de sifones color oscuro.

(Figura 2A). Posteriormente el hongo prosiguió su desarrollo y produjo esporas, el área esporulante tuvo un color verde azulado.

\section{Signos}

Por otro lado, los tejidos vegetales se llevaron a laboratorio, donde se realizó un cultivo puro observándose en la placa Petri la presencia de una colonia de coloración blanco cremosa (Figura 2B) luego se observó con la ayuda de un microscopio invertido se observó conidios esféricos, fiálides ampuliformes y estipe liso ramificado; células fialidas dispuestas estrechamente en una cabeza en forma de cepillo, conidióforos que surgen del micelio solos, ramificados (Barnett y Hunter, 1998). Todo ello correspondiente a hongos del género Penicilium (Figura 2C, 2D y 2E).

\section{Identificación de enfermedad 2}

Síntomas

En la etapa de fructificación, mostro pudrición de raíces, presentándose solo para el ají pimiento. El primer síntoma mostrado fue el amarillamiento de las hojas basales. Posteriormente se secaron, pero siguieron adheridas a las plantas. Este síntoma fue progresando hacia la parte superior de la planta. Al comienzo las plantas mostraron marchitez en las horas más calurosas del día, recuperándose al final de este, pero finalmente se marchitaron y murieron (Figura 3A).

\section{Incidencia de pulgón}

La plaga del pulgón se presentó en las cinco especies de ají. Los resultados de la ANOVA mostraron diferencias significativas entre tratamientos, siendo el ají pimiento el que tuvo mayor incidencia de pulgones por 

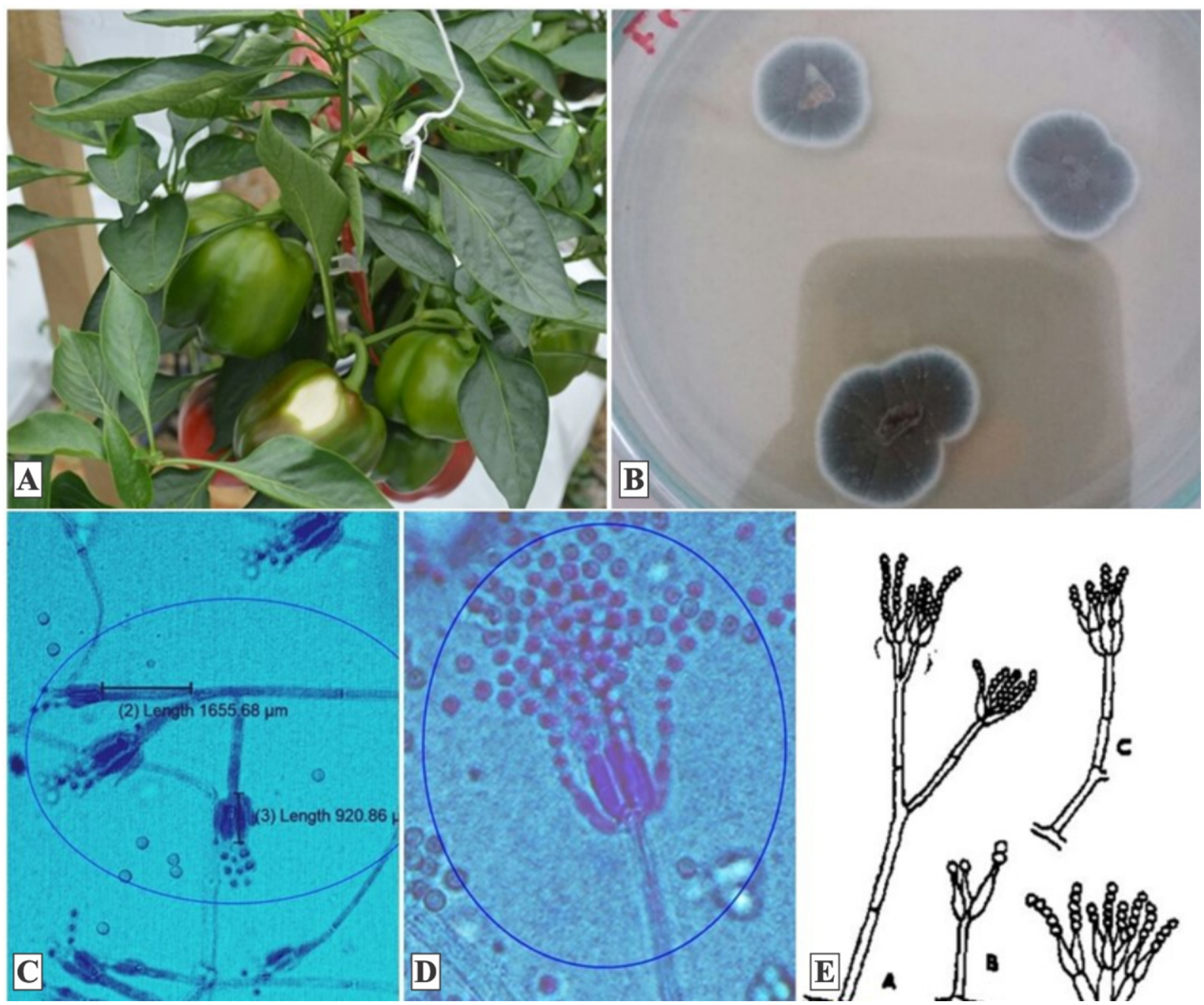

Figura 2. A, Síntomas de la enfermedad en el genotipo de ají pimiento. B, Desarrollo en placa de Petri con PDA. Cy D, Órganos reproductores del hongo fitopatógeno aislado. E, Estructura del hongo agente causal de pudrición de frutos.

pulgada cuadrada. Por otra parte, el ají pipi de mono tuvo la menor incidencia de pulgón (Figura 4).

\section{Incidencia de pudrición vascular y de los frutos}

En cuanto a la incidencia de pudrición de frutos se registró únicamente en el genotipo de ají pimiento para la pudrición vascular, mientras que las otras especies de ají no reportaron el ataque de esta enfermedad (Figura 5). Por otro lado, la pudrición de los frutos también fue exclusiva en para el genotipo de ají pimiento con el $3,8 \%$ de incidencia.

\section{DISCUSIÓN}

Las plagas identificadas en los ajíes, se deben a la presencia de áfidos de coloración verde, que estuvieron atacando los cinco genotipos de ajíes, afectando sobre todo al genotipo ají pimiento. La presencia de

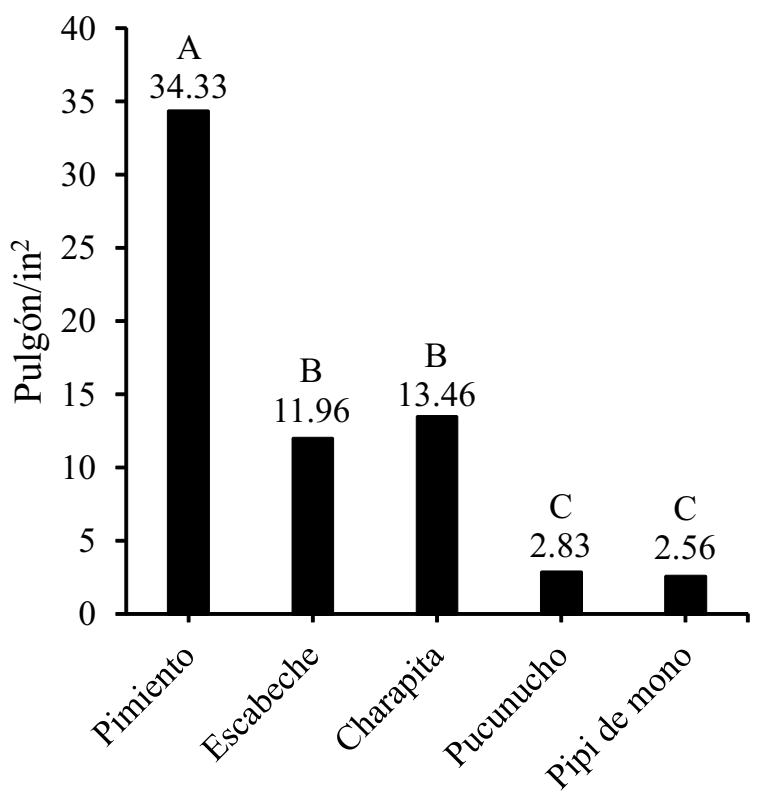

Figura 4. Incidencia del pulgón verde en los diferentes genotipos. 


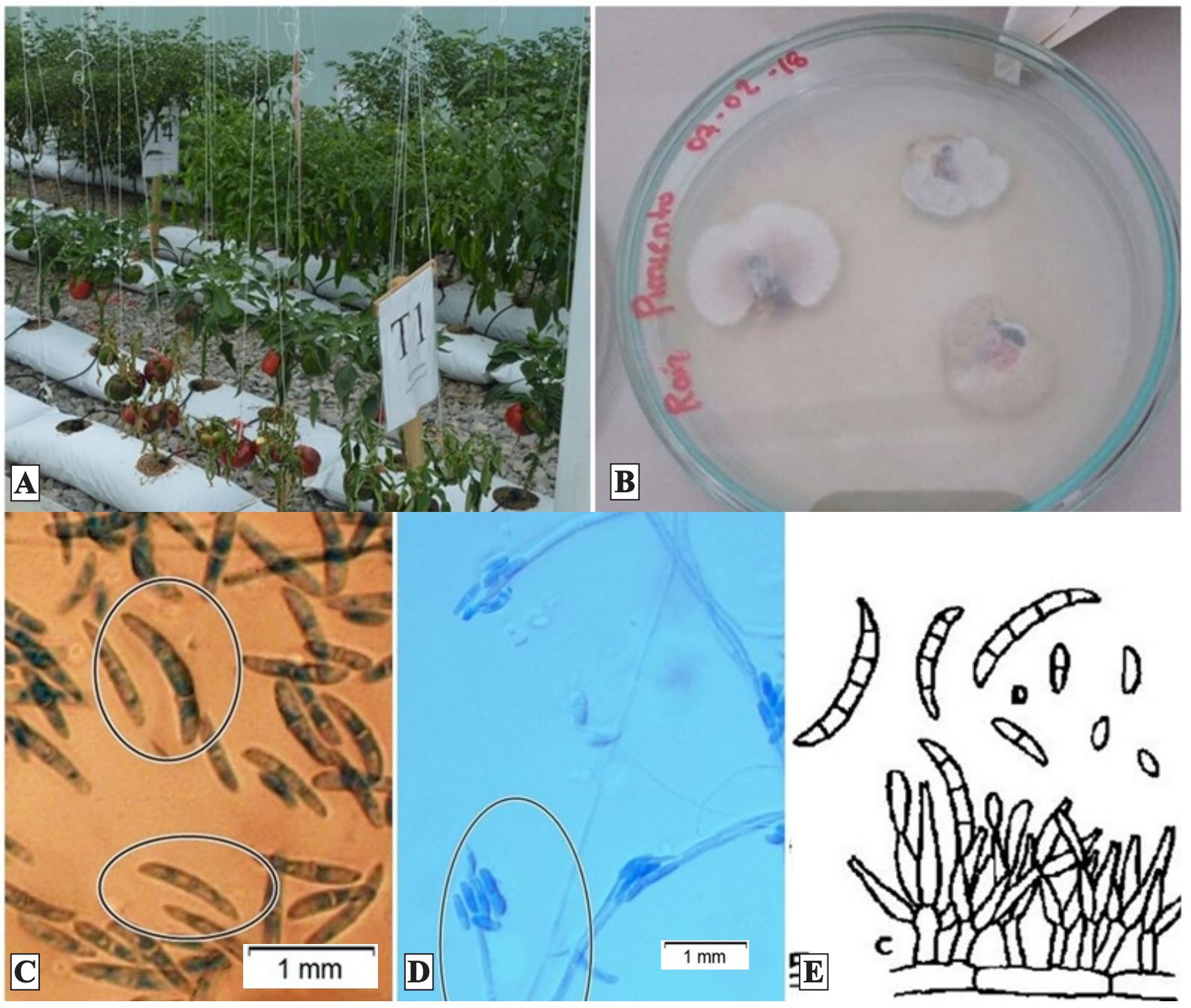

Figura 3. A, Pudrición de raíz en el ají pimiento Capsicum annuum. B, Desarrollo del hongo fitopatógeno en medio de cultivo. C y D, Estructuras del hongo fitopatógeno. E, Estructura del hongo causante de pudrición de raíz.

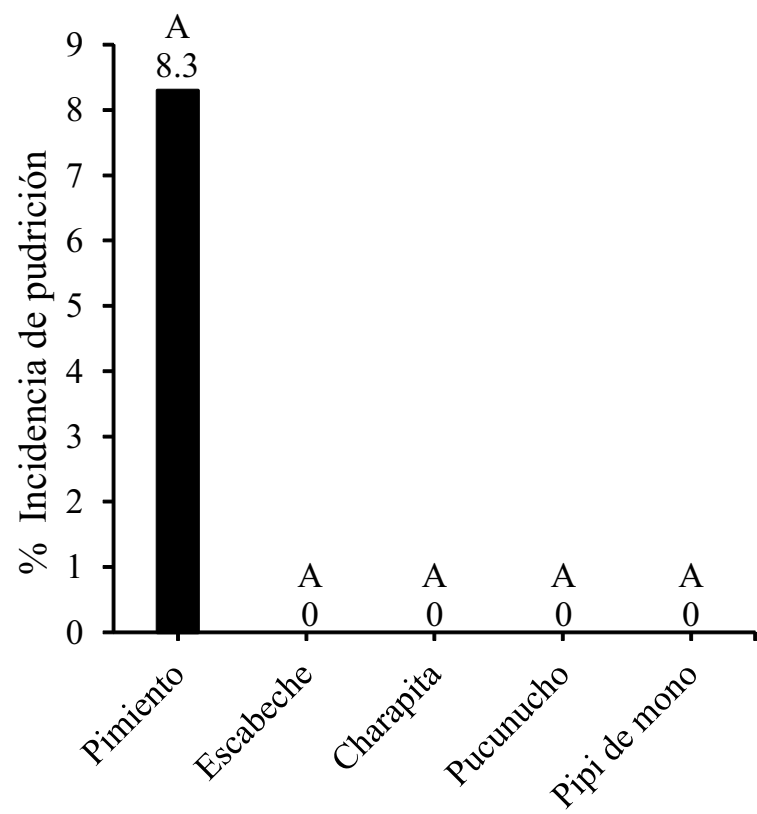

Figura 4. Incidencia de pudrición vascular en los diferentes genotipos. esta plaga es normal, ya que el pulgón es una de las principales plagas de pimientos en condiciones de invernadero (Rodríguez, 2017).

El áfido encontrado en el estudio corresponde al género Myzus, ya que las características de este género polífago, corresponden a un cuerpo color verde claro, a veces rosáceo, sifones y cauda de color verde claro. También posee sifones largos y convergentes con ápice oscuro (Navarro Campos y Ferrán García, 2014) Por otro lado, Simbaqueba et al. (2014) mencionan que los adultos del género Myzus sp, poseen color verde-amarillento claro, verde o rosáceo, cuerpo de 1,3-2,5 mm de largo. También tienen un tubérculo antenal desarrollado, con excrecencias redondeadas en el margen interior y apariencia convergente. Al mismo tiempo los adultos alados de este género 
poseen cabeza y tórax oscuro, dorso con algunas arrugas con apariencia coriácea, tubérculo bien desarrollado, con el lado interior ligeramente divergente.

En cuanto a la enfermedad de pudrición vascular registrada solo en el genotipo de ají pimiento, coincide con lo reportado por Pérez et al. (2017), donde la señalan como la principal causa de la marchitez del ají cultivado a campo abierto. La pudrición vascular o fusariosis también se encuentra identificada como una de las principales enfermedades de pimientos en condiciones de invernadero (Bojacá y Monsalve, 2012). El porcentaje de incidencia encontrado en este estudio para el ají pimiento, es bajo, considerando que en condiciones de campo abierto se reportan valores del $30 \mathrm{al}$ 60\% de incidencia (Chew et al., 2008). Cabe mencionar que el género Fusarium sp. es el causante de la pudrición vascular del ají pimiento, en el presente estudio. Este género es conocido por tener conidios con fialosporas hialinas de dos tipos: macroconidías y microconidías, conidióforos simples y ramificados y un micelio extenso y similar al algodón (Barnett y Hunter, 1998).

Asimismo, se observó el ataque de pudrición de frutos al ají pimiento con una incidencia del 3,8\%, la cual se considera baja (Alemán, 2015). Sin embargo, esta enfermedad no es exclusiva del género Capsicum, más bien se trata de una enfermedad con un amplio rango de hospederos (Arauz, 1998).

Enfatizar, que el género causante de la pudrición de frutos en el ají pimiento es Penicillium. Este género tiene esporulación de coloración blanquecina, conidios de forma fialosporas-hialinos de dos tipos: macroconidías y microconidías, conidióforos simples y ramificados y un micelio extenso y similar al algodón (Barnett y Hunter, 1998). El hongo Penicillium solo ataco al genotipo ají pimiento, probablemente por el efecto de la cantidad de capsaicina que contiene el fruto de pimiento con relación a los otros genotipos. Esto se debe a que el genotipo de ají pimiento contiene una menor cantidad de capsaicina en el fruto que los genotipos de ají escabeche, ají charapita, ají pucunucho y ají pipi de mono (Yánez et al., 2015). Cabe resal- tar que se encontró afecto anti fúngico exhibido por la capsaicina contra Penicillium expansum en condiciones in vitro (Fieira et al., 2012). Sin embargo, la enfermedad pudrición de frutos causado por Penicillium podría tratarse de una infección secundaria debido a que el síntoma observado en invernadero podría tratarse de alguna injuria (quemadura de sol, deficiencia nutricional, etc.), al saberse que los hongos del género Penicillium son oportunistas (Zhu et al., 2019).

\section{CONCLUSIONES}

La principal y única plaga que afecto a los cinco genotipos de ají, se debe a un pulgón verde del genero Myzus (Familia: Aphididae). Por otra parte, la presencia de los hongos de los géneros Fusarium y Penicillium en el genotipo ají pimiento, son los agentes causales de enfermedades de pudrición vascular y pudrición de frutos, respectivamente.

El nivel de incidencia causado por pulgón verde alcanzó un promedio de 34,33 pulgones/in². Mientras que las incidencias de Fusarium y Penicillium fueron del $3,8 \%$ y el $8,3 \%$ respectivamente, siendo el ají pimiento el único genotipo afectado.

\section{REFERENCIAS BIBLIOGRÁFICAS}

Agrarios, G. N. N. 1995. Fitopatologia. Ciudad de México (México): LIMUSA.

Alemán. R. D., J. Domínguez, Y. Rodríguez, S. Soria, R. Torres, J. Vargas, C. Bravo, y J. Alba. 2018. "Indicadores morfofisiológicos y productivos del pimiento sembrado en invernadero y a campo abierto en las condiciones de la Amazonía ecuatoriana." Revista Centro Agrícola 45 (1): 14 - 23.

Alemán, L. 2015. Control de las podredumbres de pimiento (Capsicum annuum var. California) con ácido peroxiacético. Tesis de grado. Universidad Politécnica de Cartagena. Cartagena (Colombia).

Arauz, L. F. 1998. Fitopatología un enfoque agroecológico. San José (Costa Rica): Editorial de la Universidad de Costa Rica.

Barnett, H. L., y B. B. Hunter. 1998. Illustrated Genera of Imperfect Fungi. Minnesota (Estados Unidos): 
Press The American Phytopathological Society.

Beatriz, N. 2015. "Producción de hortalizas bajo invernaderos (fitotoldos), en la mejora de la alimentación familiar en zonas Altoandinas.” En V Congreso Latinoamericano de Agroecología - SOCLA. La Plata (Argentina).

Belmontes, J. R., y C. Castañeda. 2015. “Evaluación del insecticida kensei ${ }^{\circledR}$ (clorpirifos + lamdacyhalotrina) para el control de pulgón amarillo en sorgo (Melanaphis sacchari) en la comunidad de Lazaro Cardenas, Texistepec, Veracruz. 2015”. Investigación y Desarrollo Gowan Mexicana: 4 - 9.

Beltrano, J. y D. O. Gimenez. 2015. Cultivo en hidroponía. Buenos Aires (Argentina): Editorial de la Universidad de La Plata.

Cabello, T., M. Torres y, P. Barranco. 1997. Plaga de los cultivos: guía de identificación. Almería (España): Universidad de Almería.

Chew Madinaveitia, Y. L., A. Piña-Vega, M. PalomoRodríguez, y F. Jiménez Díaz. 2008. Principales enfermedades del Chile (Capsicum annuum L.). Ciudad de México (México): Sagarpa.

Ellis, M. B. 1971. Dematiaceous hyphomycetes. Londres (Inglaterra): Commonwelth Agricultural Bureaux.

FAO (Organización de las Naciones Unidas para la Alimentación y la Agricultura). 2002. Manual práctico MIP y enfermedades en cultivos hidropónicos en invernadero. Almeria (España): IDEABOOKS.

Fieira C., F. Oliveira, R. Calegari, A. Machado, y A. Coelho. 2012. "In vitro and in vivo antifungal activity of natural inhibitors against Penicillium expansum Inibidores naturais no controle in vitro e in vivo de Penicillium expansum." Ciência e Tecnologia de Alimentos 33: 40 - 46.

Juárez, P., R. Bugarín, R. Castro, A. L. Sánchez, E. Cruz, C. R. Juárez, G. Alejo, y R. Balois. 2011. "Estructuras utilizadas en la agricultura protegida." Revista Fuente 3 (8): 21-27.

Navarro Campos, C., y F. Garcí-Marí. 2014. Guía de identificación Pulgones y sus enemigos naturales. Valencia (España): Universitat Politècnica de València.

Ortego J., M. E. Difabio, y M. P. Mier Durante. 2009. "Nuevos registros y actualización de la lista faunística de los pulgones (Hemíptera: Aphididae) de la Argentina." Revista de la SociedadEntomológica Argentina 63 (1-2): 19 - 30.

Pérez C., J. Carrillo, J. Chávez, C. Perales, R. Enriquez, y Y. Villegas. 2017. "Diagnóstico de síntomas y patógenos asociados con marchitez del chile en Valles Centrales de Oaxaca." Revista Mexicana de Ciencias Agrícolas 8 (2): 281-293.

Rodríguez, N. 2017. Ensayo de tres variedades de pimiento (Capsicum annuum L.) de tipo Lamuyo en dos tipos de invernaderos y en distintos sistemas de cultivo. Tesis de grado. Universidad de La Laguna. Santa Cruz de Tenerife (España).

Simbaqueba R., F. Serna, y F. J. Posada. 2014. “Curaduría, morfología e identificación de áfidos (Hemiptera: Aphididae) del museo entomológico UNAB." Boletín Cientifico Centro de Museos Museo de Historia Natural 18 (1): 222-246.

Tomalo, M. A. 2015. Caracterización morfológica de hongos fitopatógenos en el cultivo de fresa (Fragaria vesca) en el sector de Salache Barbapampa, canton Salcedo, Cotopaxi 2015. Tesis de grado. Universidad Técnica de Cotopaxi. Cotopaxi (Ecuador).

Ugas, R. 2012. Clasificación de ajíes del Perú. Lima (Perú): UNALM.

Yánez P., D. Balseca., L Rivadeneira., y C. Larenas. 2015. "Características morfológicas y de concentración de capsaicina en cinco especies nativas del género capsicum cultivadas en Ecuador." Revista de ciencias de la vida 22 (2): 12-32.

Zhu C., M. Lei, M. Andargie, J. Zeng, y J. Li. 2019. "Antifungal activity and mechanism of action of tannic acid against Penicillium digitatum." Physiological and Molecular Plant Pathology 107: 46-50. 